\title{
Role of modern radiological investigations in obstructive uropathy
}

\author{
P H O'REILLY
}

\begin{abstract}
Obstructive uropathy in its various forms accounts for much of the work load in urological units and general hospitals. Until recently, laboratory tests and excretion urography were the only procedures available for its assessment. The past few years have seen the development and refinement of ultrasound, examination by computed tomography, nuclear medicine, antegrade pyelography, and perfusion pressure flow studies. This paper examines the particular qualities of these modern procedures and their role in the clinical assessment of the obstructed urinary tract.
\end{abstract}

\section{Introduction}

A major problem in any discussion of the investigation and management of obstructive uropathy is the difficulty in precisely defining what that term means. This is partly due to its complex pathophysiology. Impedance to the flow of urine, urinary tract dilatation, reduction in flow rate, varying intrarenal pressures, and functional impairment all play a part in the development of the syndrome, although the individual part each plays in producing renal damage is not fully understood (fig 1). For example, raised intrarenal pressures are generally considered to have an essential influence on the pathogenesis of renal damage in obstruction, yet measurements in chronic obstructive states are often normal. ${ }^{1-3}$ Similarly, in experimental

Department of Urology, Stepping Hill Hospital, Stockport SK2 7JE P H O'REILLY, MD, FRCS, consultant urological surgeon

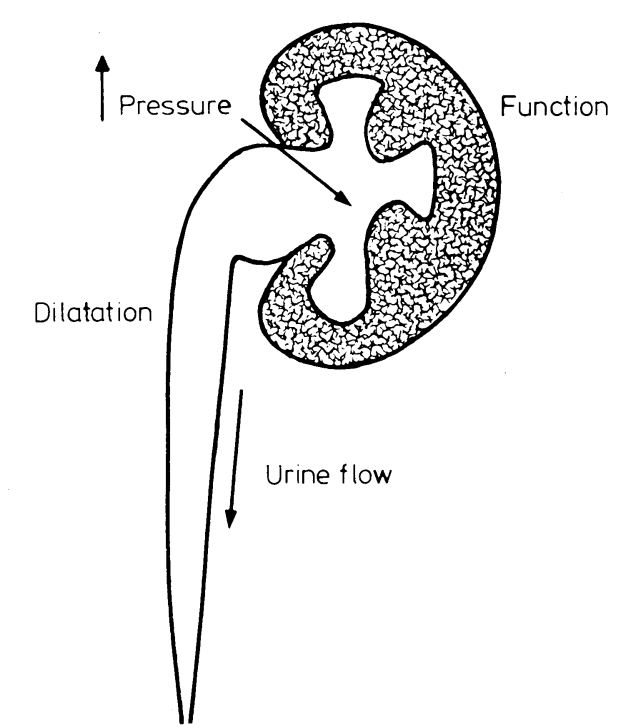

FIG 1-Obstructive uropathy. Pathophysiological considerations.

partial ureteric occlusion studies intrapelvic pressures have been shown to remain normal while dilatation actually persists or even progresses, ${ }^{4-9}$ making any consideration of obstructive uropathy based on a simplistic concept of raised pressure invalid. If emphasis is placed instead on urine flow rather than pressure then static anatomical means of assessment such as urographic appearances will not be reliable. The independence of dilatation and obstruction and the appreciation that they are mutually exclusive has radically changed the clinical evaluation of urine flow in obstruction and demanded new urodynamic means to assess the dilated upper urinary tract. A third option 
is to concentrate on the primary motive behind the management of obstructive uropathy-that is, the preservation of renal function. This renders subjective or anatomical means of evaluation redundant and demands accurate objective divided renal function measurements if this concept is to be used as a basis for definition and management.

With these points in mind, the task of the clinician is directed towards diagnosing and removing the obstruction, preserving renal function, and hopefully reversing any damage that may have occurred. In acute obstruction all these may be possible. In the chronic state, selection and timing for surgery are far from straightforward and may be complicated by decisions about which kidney to operate on first in bilateral disease, the persisting effects of previous obstruction or surgery in recurrent disease, and the need to distinguish between patients with true obstruction and those with similar urographic appearances from non-obstructive dilatation or ureteric reflux.

The table shows the procedures available for reaching an appropriate management decision. Like many modern investigative options, informed and wise use should result in maximum information while ill-informed and blanket use will be expensive and counterproductive. Their use needs to be tailored in the light of the physiological considerations discussed above to the existing clinical conditions. To this end it is useful to divide the all-embracing term "obstructive uropathy" into various subgroups (fig 2) and to consider them individually.

Investigations available for assessing obstructive uropathy

Laboratory tests

Intravenous urography

Antegrade urography

Ultrasound

Radionuclide studies

Gamma-camera renography

Diuresis renography

Parenchymal transit time studies

Perfusion pre

Cystourethroscopy


FIG 2-Various subgroups of obstructive uropathy.

\section{Upper tract obstruction}

\section{ACUTE OBSTRUCTION}

The patient with acute obstruction is immune to most of the above problems. The condition is often encountered in clinical practice (stone disease alone is responsible for $7 \%$ of urgent admissions to general hospitals). It is in acute obstruction that the excretion urogram is of greatest value. The maintenance of renal blood flow and glomerular filtration combined with slow (obstructed) intratubular transit of urine means that input exceeds output and the diagnostic dense nephrogram is produced. Delayed pictures will usually show a dilated pelvicalyceal system or ureter down to the level of the obstructing lesion. If ureteric visualisation fails to occur, retrograde ureterography will delineate the anatomy and site of obstruction. Ultrasound, examination by computed tomography, and antegrade studies are unlikely to be needed. Gamma-camera renography may be useful to establish an objective baseline of divided renal function and to monitor its response to conservative or surgical management, and is of considerable value combined with a plain abdominal radiograph in making the initial diagnosis in patients allergic to contrast media.

\section{UNEQUIVOCAL CHRONIC OBSTRUCTION}

Stones, ureteroceles, retroperitoneal fibrosis, ureteric tumours, and extrinsic malignancies, such as those affecting the colon and pelvic organs, are just some examples of conditions where the urinary tract may be unequivocally obstructed by a demonstrable organic lesion (fig 3). In most of these conditions clinical examination and radiological imaging by excretion urography, retrograde ureterography, ultrasound, examination by computed tomography, or contras studies will make a definite diagnosis, and surgical intervention will be forthcoming. While diagnosis of the underlying cause may be relatively straightforward, one further piece of information is essential to management-the underlying divided renal function with its resulting decision regarding nephrectomy or conservation.

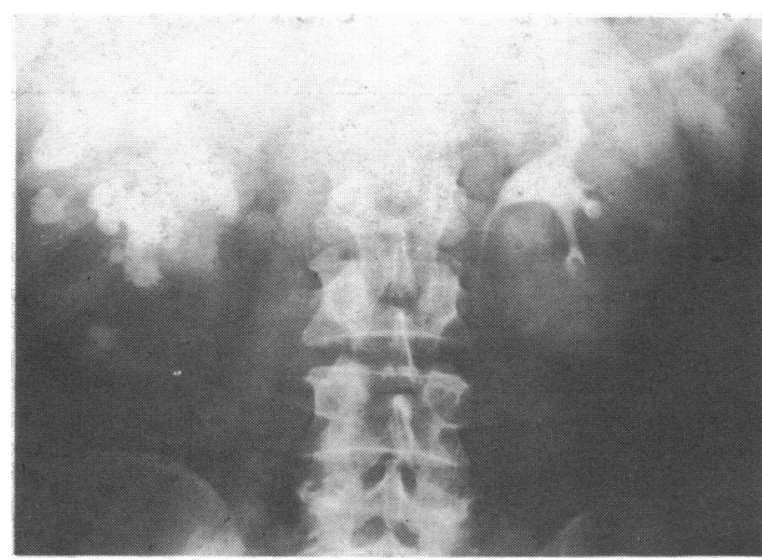

FIG 3-Chronic right upper tract obstruction-stone disease.

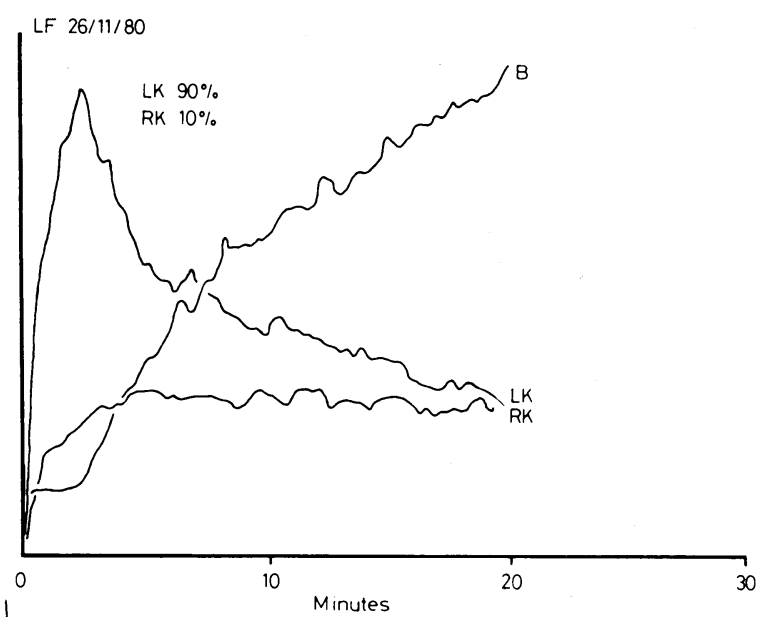

FIG 4-123 I-hippuran gamma-camera renography showing dynamic time-activity curve and computer-derived differential renal function.

RK= Right kidney LK=Left kidney $; B=$ Bladder.

It is here that nuclear medicine procedures have contributed what is probably the most significant advance in investigative clinical urology since the introduction of the intravenous pyelogram-the ability to measure quantitatively and non-invasively individual renal function. Routine laboratory evaluations, such as blood urea or blood urea nitrogen, serum creatinine concentration, creatinine clearance, or maximum urinary concentrating ability, rely on measurements of total capability. Conventional divided clearances or concentrating ability require selective ureteric catheterisation with the likelihood of failure to pass the obstruction, or the introduction of infection into 
an already compromised urinary tract with disastrous consequences. Gamma-camera renography using ${ }^{123} \mathrm{I}$-hippuran or ${ }^{99 \mathrm{~m}} \mathrm{TC}-\mathrm{DTPA}$ will objectively analyse the accumulation, transit, and elimination of injected activity by each kidney to produce the well-known timeactivity curves (fig 4). The simple and non-invasive nature of the procedure is an added advantage, and it is at last becoming widely used both in its simple and its more sophisticated forms. ${ }^{10-14}$ This development has in no small way resulted from a growing appreciation of the unreliability of the excretion urogram as an indicator of the functional state of the kidneys. The anatomical size of the kidneys means little. It is possible to have a hugely dilated pelvicalyceal system with an apparently thin but merely attenuated and potentially normal rin of parenchyma on its periphery. The physiological determinants of urographic contrast visualisation and the lack of standardisation of dose on a volume-for-weight basis combine grossly to obscure reductions in function. ${ }^{15}$ This is compounded by misleadingly excellent collecting system visualisation and by the subjective "eyeballing" nature of urogram interpretation with its large observer bias. The radionuclide methods are free from these disadvantages. They are objective, quantitative, and dynamic, and accurately complement the anatomical urogram data.

Unfortunately no convincing method exists at present to predict preoperatively recovery of renal function after relief of chronic unequivocal obstruction. The nearest approach lies in percutaneous puncture of the renal pelvis using modern pig-tail catheters, which will allow antegrade pyelography to determine the site of obstruction and subsequent decompression of the system. If such decompression results in recovery of function conservation may be recommended. This remains the only practical prognosticator at present, and it can be of considerable value in selected cases. Its invasive nature should stimulate efforts to replace it with a non-invasive alternative.

\section{EQUIVOCAL CHRONIC OBSTRUCTION}

Urinary tract dilatation without a demonstrable organic lesion to account for it is a common urological problem (fig 5). It may occur in idiopathic hydronephrosis, primary megaureter, and vesicoureteric reflux, or after operations such as pyeloplasty, pyelolithotomy, ureterolithotomy, ureteric reimplantation, and urinary diversions. It is indefensible to operate on a dilated urinary tract without objective evidence that it is obstructed, and equally dangerous not to operate where obstruction exists. This dilemma has resulted in the development of three special methods to clarify such cases-diuresis renography, radionuclide parenchymal transit time estimations, and pressure flow studies.

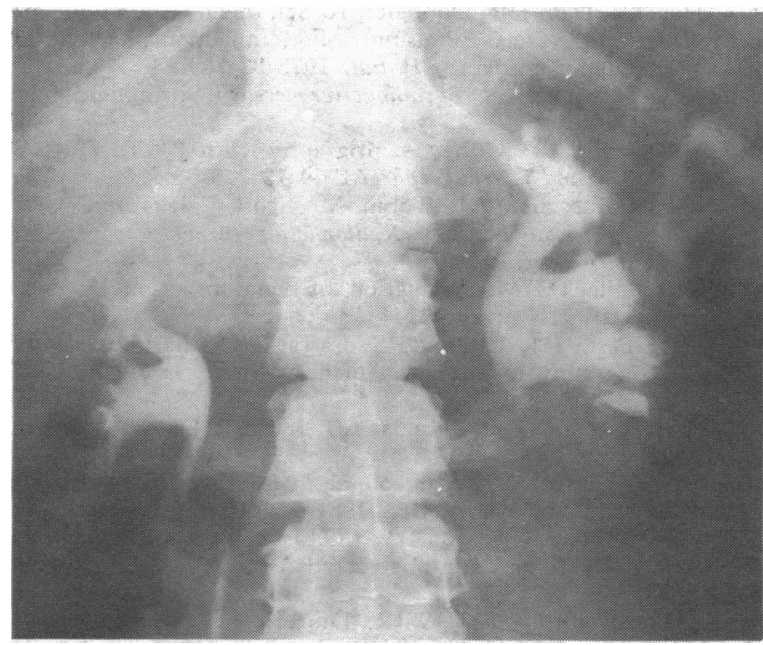

FIG 5-Dilated left pelvicalyceal system-obstructed?

\section{Diuresis renography}

The principle behind diuresis renography is that in a genuinely obstructed upper urinary tract obstruction will be present at low and high urine flow rates. In a dilated non-obstructed system an artefactually obstructed renogram curve caused by stasis in the dilated system will be unmasked by diuresis, and washout of radionuclide will occur from the upper tract. The technique is simple. After a standard ${ }^{123} I$-hippuran $\gamma$-camera renogram, one of three modifications is used:

(1) If the standard renogram is normal it is repeated three minutes after an intravenous injection of $0.5 \mathrm{mg} / \mathrm{kg}$ frusemide.

(2) If the standard renogram is obstructive with no elimination at 20 minutes, the frusemide is given continuously while the tracing continues uninterrupted.

(3) If the renogram shows spontaneous but slow elimination the frusemide is given continuously but the test is repeated giving the diuretic from the start if there is any difficulty in interpretation.

Four responses may occur:

(a) Both renograms are normal excluding obstruction.

(b) Both renograms are obstructive confirming genuine obstruction.

(c) An initially obstructive curve is converted to normal with rapid, complete elimination of tracer, indicating a dilated but non-obstructed system.

(d) An obstructive curve shows a partial response only to diuresis indicating a subtotal degree of obstruction or a kidney functioning too poorly to respond maximally to the diuretic.

\section{Parenchymal transit time estimations}

Parenchymal transit time estimations, using ${ }^{99 \mathrm{~m}} \mathrm{Tc}$-DTPA, relies on the ability of the $\gamma$-camera to distinguish between regions of interest within the parenchyma and within the collecting system. This is done by displaying the renogram data not only as a variation of count rates with time but also as a functional image of the distribution of mean transit times, which makes renal pelvic imaging very accurate. Deconvolution analysis of the whole kidney curve with the pelvic curve subtracted gives an accurately quantified parenchymal transit analysis. In significant obstruction both whole kidney and parenchymal transit are prolonged, while in the dilated non-obstructed system whole kidney transit may be prolonged but parenchymal transit is not.

\section{Perfusion pressure flow studies}

Perfusion pressure flow studies entail the percutaneous antegrade puncture of a dilated renal pelvis or ureter proximal to the site of suspected obstruction and perfusion of saline or contrast medium at a fixed rate of $10 \mathrm{ml} / \mathrm{min}$. If the pressure rises above $22 \mathrm{~cm} \mathrm{H}_{2} \mathrm{O}$ during perfusion obstruction is said to be diagnosed. A rise of under $15 \mathrm{~cm} \mathrm{H}_{2} \mathrm{O}$ excludes obstruction, while the intervening range is equivocal.

All these procedures have their own advantages and disadvantages. The diuresis renogram gives simultaneous evaluation of function and urodynamics under normal and high flow states. It is non-invasive, simple to perform, and repeatable at frequent intervals. Reports from several centres have confirmed its value. ${ }^{16-22}$ It requires some renal function if information on urodynamic behaviour is to be obtained. A normal response may be expected down to clearances of $15 \mathrm{ml} / \mathrm{min}$. Below this level, the effect of small doses of intravenous frusemide is less predictable and below $4 \mathrm{ml} / \mathrm{min}$ the technique is of no value because of the combination of poor tracer uptake and poor diuretic response. Parenchymal transit time estimations are similarly non-invasive and give quantitative objective information on parenchymal state, monitoring the effect of obstruction on tubular function to distinguish beıween hypotonia and obstruction. ${ }^{23}$ The mapping of areas of interest and separation of dilated calyces from parenchyma takes considerable skill, however, and the time of onset of delayed transit and specificity of the results for obstructive as opposed to other forms of nephropathy is still uncertain. Perfusion pressure flow studies are a more direct approach to assess the ability of the renal collecting system to transport fluid. ${ }^{24}$ They assume the premise that if the ureter will not transmit perfusate at $10 \mathrm{ml} / \mathrm{min}$ without an inordinate pressure rise, then surgical intervention is necessary. They are invasive, unsuitable for repeat studies, and give no information on renal function, though they do not require function for their performance.

All these techniques are now accepted in clinical practice and are undergoing continuing scientific evaluation. ${ }^{26-28}$ They represent an impressive and considerable advance in accurately assessing over $80 \%$ of patients who, before their availability, represented a huge clinical 
problem. Their individual and combined application to equivocal obstruction has been a considerable help to the clinician faced with making the correct management decision.

\section{NON-FUNCTIONING KIDNEY}

The finding of a urographic non-functioning kidney raises several questions. Is the kidney present? If so is non-opacification due to irreversible parenchymal disease or reversible obstruction? If the latter how long has it been present and what is the likelihood of functional improvement if the condition is operated on? Ultrasound is the first investigation of choice. Its simple, non-invasive nature promotes it above retrograde ureteropyelography (which is invasive and carries the risk of introducing infection into an already compromised urinary tract), radionuclide studies, and examination by computed tomography. Its value is two-edged. It should quickly ascertain if the kidney is present, and if so whether the calyces are dilated (suggesting an obstructive aetiology) or not. Agenesis may ultimately require cystoscopy to show an absent hemitrigone, while radionuclide scanning or examination by computed tomography will help to locate ectopic renal tissue if this is suspected as a cause for non-opacification in the normal anatomical position. Two recent reports suggest that vascular isotope scanning to assess renal blood flow in non-functioning kidneys ${ }^{29}$ and delayed ${ }^{131} I$-hippuran $\gamma$-camera scanning, which will show many kidneys that are not visible urographically, ${ }^{30}$ may be of further value in complementing the anatomical information available from ultrasound. It should be added that with modern high dose urogram techniques and nephrotomography, the vast majority of kidneys will be visible urographically. Such studies are not always performed de novo, however, and the standard urogram that shows a non-functioning kidney is better followed up by ultrasound and isotope studies than by bringing the patient back for further urograms.

\section{LOWER URINARY TRACT OBSTRUCTION}

Some rethinking of the traditional approach to obstruction of the lower tract has been evident in recent years. It was once automatic for patients with acute and chronic urinary retention or prostatic symptoms to have excretion urography before surgery. Experience has suggested, however, that most patients with exclusively lower tract symptoms may not justify comprehensive upper tract investigation. In acute retention, for example, many urologists would now settle for a plain abdominal film to exclude stones and press on with transurethral prostatectomy, reserving excretion urography for those cases where it is particularly indicated-for instance, the patient with haematuria. In chronic retention urography is interesting in showing that group with high pressure chronic retention with dilated upper tracts, yet it rarely contributes directly to patient management and might be just as appropriate after surgery to show return to normality of the upper tracts. As for the third group of patients-those with uncomplicated "prostatism"- the detection of incidental pathology is the main reason for urography, since the procedure gives virtually no reliable quantitative data on renal function, urodynamics, flow rates, or residual urine. A radionuclide urogram will give all this information. ${ }^{31}$ It is such considerations that have led to attempts to modify the standard urogram ${ }^{32}$ or to carry out studies to investigate its necessity in dysfunction of the lower tract. ${ }^{33}$ The question is in the urological melting pot at present, but, pending further studies, while urologists may be prepared to forego the intravenous pyelogram in acute retention, patients with prostatism are likely to continue to be advised to have an intravenous pyelogram, particularly when, as is the case in many centres, their subsequent wait for transurethral surgery may be anything up to two to four years.

\section{Conclusions}

In the standard uronephrological practice obstruction will comprise a large proportion of day-to-day clinical work. Until recently, laboratory tests and urography were the only procedures available to examine the renal state. Happily, ultrasound and examination by computed tomography have now been added to the imaging armamentarium, and advanced nephrotomography and antegrade pyelography have become more widely used. None of these procedures, however, gives detailed information on the two parameters of most importance in obstructive uropathy - that is, divided renal function and upper tract urodynamics. Fortunately this deficiency has been corrected by the development of urological nuclear medicine. Consequently the establishment of quantitative divided function, the ability to monitor upper tract urodynamics, the means to monitor changes with respect to treatment and the distinction between genuine obstruction and other conditions that may mimic it are also within the realms of clinical possibility.

Without these developments dynamic functional assessments in obstructive uropathy could not be made with any degree of objective confidence. Reliance would be placed instead on criteria such as contrast opacification, pelvicalyceal and ureteric dilatation, or kidney size. Patients would run the risk of inaccurate assessment or inappropriate surgery without any objective means to justify such decisions. Fortunately, the combination of specialised nuclear medicine with the various available radiological imaging procedures has allowed the urologist to assess obstructive uropathy according to the physiological criteria laid down in the opening paragraphs, with resulting benefit to the patient in his care.

\section{References}

${ }^{1}$ Underwood WE. Recent observations on the pathology of hydronephrosis. Proc R Soc Med 1937;30:817-20.

-Kiil F. The function of the renal pelvis and ureter. Oslo: University Press, 1957.

${ }^{3}$ Djurhuus JC, Nerstrom B, Hansen RI, Rask Anderson H. Incomplete ureteral duplication. Scand f Urol Nephrol 1976;10:111-4.

${ }^{4}$ Schweitzer FAW. Intra pelvic pressure and renal function studies in experimental chronic partial ureteric obstruction. Br f Urol 1973;45: $2-7$.

5 Djurhuus JC, Nerstrom B, Gyrd-Hansen N, Rask Anderson H. Experimental hydronephrosis. An electrophysiologic investigation before and after release of obstruction. Acta Chir Scand (suppl) 1976;472:17-28.

${ }^{6}$ Weaver RG. Reabsorptive patterns and pressures in hydronephrosis with a clinical application. 7 Urol $1968 ; 100: 112-8$.

${ }^{7}$ Boyarsky S, Martinez S. Pathophysiology of the ureter: partial ligation of the ureter in dogs. Invest Urol 1964;2:173-80.

${ }^{8} \mathrm{Koff} \mathrm{SA}$, Thrall JH. The diagnosis of obstruction in experimental hydroureteronephrosis. 7 Urol (in press).

9 Weiss RM. Ureteral obstruction. Dialogues in Pediatric Urology 1980; $3: 2-3$.

${ }^{10}$ Buck C, Macleod MA, Blacklock NJ. The advantages of ${ }^{99_{\mathrm{m}} \mathrm{Tc}-\mathrm{DTPA}}$ in dynamic renal scintigraphy and measurement of renal function. Br 7 Urol 1980;52:174-87.

${ }^{11}$ Piepz A, Denis R, Ham HR, Dobbeleir A, Schulman C. A simple method for measuring separate GFR using a single injection of $99_{\mathrm{m}} \mathrm{Tc}-\mathrm{DTPA}$ and the scintillation camera. F Pediatr 1978;93:769-74.

${ }^{12}$ Raynaud EC. The renal uptake of radioactive mercury. Springfield: Thomas, 1978.

${ }^{13}$ Holten I, Storm HH. Kidney scintigraphy with $99 \mathrm{~m}$ Tc-DMSA and ${ }^{131}$ I hippuran. Scand f Urol Nephrol 1979;13:275-83.

${ }^{14}$ Dubovsky EV, Bueschen AJ, Tobin M, Scott JW, Tauxe WN. In: Hollenberg NK, Lange S, eds. Radionuclides in nephrology. Stuttgart: Georg Thieme Verlag, 1980.

${ }^{15}$ Banner MP, Pollack HM. Evaluation of renal function by excretory urography. $\mathcal{F}$ Urol 1980;124:437-43.

${ }^{16}$ O'Reilly PH, 'Testa HJ, Lawson RS, Farrar DJ, Charlton Edwards E. Diuresis renography in equivocal urinary tract. $B r f$ Urol 1978;50: 76-80.

${ }^{17}$ O'Reilly PH, Lawson RS, Shields RA, Testa HJ. Idiopathic hydronephrosis. F Urol 1979;121:153-5.

${ }^{18}$ O'Reilly PH, Gosling JA, eds. Idiopathic hydronephrosis. Berlin, Heidelberg, New York: Springer Verlag, 1982

19 O'Reilly PH, Lupton EW, Testa HJ, Shields RA, Carroll RNP, Charlton Edwards E. The dilated non-obstructed renal pelvis. Br f U Urol 1981; 53:205-10.

${ }^{20}$ Koff SA, Thrall JH, Keyes JWJR. Diuretic radionuclide urography. 7 Urol 1979;122:451-4.

${ }^{21}$ Kreuger RP, Ash JM, Silver MM, et al. Primary hydronephrosis. Urol Clin North Am 1980;7:231-6.

22 Stage $\mathrm{KH}$, Lewis S. Use of radionuclide washout test in evaluation of suspected upper urinary tract obstruction. F Urol 1981;125:379-86.

23 Whitfield $\mathrm{HN}$, Britton KE, Hendry WF, Nimmon CC, Wickham JEA. The distinction between obstructive uropathy and nephropathy by radio-isotope transit times. Brf Urol 1978;50:433-6.

${ }^{21}$ Pfister RC, Newhouse JH. Antegrade pyelography and ureteral perfusion. Radiol Clin North Am 1979;17:341-50.

${ }^{25}$ Whitaker RH. The Whitaker test. Urol Clin North Am 1979;6:529-39. 
${ }^{26}$ Lupton EW, O'Reilly $\mathrm{PH}$, Testa $\mathrm{HJ}$, et al. Diuresis renography and morphology in urinary tract obstruction. Br 7 Urol 1979;51:10-5.

${ }^{27}$ Lupton EW, Testa HJ, Lawson RS, Charlton Edwards E, Carroll RNP, Barnard RJ. Diuresis renography and the results of surgery for idiopathic hydronephrosis. Br F Urol 1980;51:449-53.

${ }^{28} \mathrm{Koff}$ SA. Experimental validation of diagnostic methods in idiopathic hydronephrosis. In: O'Reilly $\mathrm{PH}$, Gosling JA, eds. Idiopathic hydronephrosis. Berlin, Heidelberg and New York: Springer Verlag, 1982.

${ }^{29}$ Lome L, Persky S, Levy L. Dynamic renal scanning in the non-visualised kidney. F Urol 1979;121:148-53.

${ }^{30}$ Sherman RA, Blaufox MD. Clinical significance of non-visualisation with ${ }^{131}$ I hippuran renal scan. In: Hollenberg NK, Lange $S$, eds. Radionuclides in nephrology. Stuttgart: Georg Thieme Verlag, 1980.

${ }^{31}$ O'Reilly PH, Lawson RS, Shields RA, Testa HJ, Charlton Edwards E Radionuclide studies of the lower urinary tract. $B r \mathcal{F}$ Urol 1981;53: 266-70.

32 Turner Warwick R, Whiteside CG, Milroy EJ, Pengelly AW, Thompson DT. The intravenous urodynamogram. Br $\mathcal{F}$ Urol 1979;51:15-9.

${ }^{33}$ Puick BD, Corrigan MJ, Hasper P. Pre-prostatectomy excretory urography: does it merit the expense ? F Urol 1980;123:390-5.

(Accepted 23 March 1982)

\title{
Lesson of the Week
}

\section{Severe bleeding disorders in children with normal coagulation screening tests}

\author{
G P TAYLOR
}

Congenital bleeding disorders may present in many ways, usually doing so in infancy or early childhood. In any child presenting with unexplained bruising one must also consider the possibility of non-accidental injury. In many cases it may be impossible to exclude non-accidental injury because the history and signs may only be pointers, the true facts becoming apparent only by careful follow-up.

I report on two children in whom the diagnosis of possible non-accidental injury, along with "normal clotting studies," led to delayed diagnosis of congenital bleeding disorders.

\section{Case 1}

A 10-month-old West Indian child was admitted for observation at the mother's request because of irritability. He had reportedly been throwing himself about his cot. Initially on examination he had only occipital bruising, with no other abnormal signs. The mother was young, unmarried, and pregnant with a further unwanted child. She had two other normal, well children. She was a regular clinic attender and had also seen her general practitioner because of the baby's "horrendous bruises." Non-accidental injury had been suspected. There was no family history of bleeding or tendency to bruise. The next morning the bruising had become a large occipital and periorbital haematoma, with further ecchymoses over the upper arms, wrist, and shins. On further questioning the mother mentioned non-accidental injury herself. The results of investigations showed: haemoglobin concentration $5.3 \mathrm{~g} / \mathrm{dl}$ (reticulocytes $8.3 \%)$; platelet concentration $247 \times 10^{9} / 1 \quad\left(247000 / \mathrm{mm}^{3}\right)$; prothrombin time $13 \mathrm{~s}$ (control $12 \mathrm{~s}$ ); partial thromboplastin time $59 \mathrm{~s}$ (control $55 \mathrm{~s}$ ); bleeding time (Ivy) $6 \frac{1}{2} \mathrm{~min}$ (normal 2-7); skeletal survey normal; serum iron concentration $8 \mu \mathrm{mol} / 1$ (45

St Charles Hospital, London W10

G P TAYLOR, MB, MRCP, paediatric registrar (present appointment research fellow, Departments of Paediatrics and Immunology, Royal Postgraduate Medical School, Hammersmith Hospital, London W120HS)
When non-accidental injury is suspected it is important to exclude a bleeding disorder by careful screening of haemostasis

$\mu \mathrm{g} / 100 \mathrm{ml}$ ) (normal $14-29 \mu \mathrm{mol} / 1 ; 78-162 \mu \mathrm{g} / 100 \mathrm{ml}$ ). The child had a blood transfusion, and a case conference was arranged.

After two days the right pupil was smaller than the left, the left knee jerk had become brisk, there was neck retraction, and the level of consciousness varied. He was transferred to the regional neurosurgical unit because of presumed intracranial bleeding. Investigations, including computed tomography and lumbar puncture, were normal, however. After the infant returned the right thigh appeared swollen, though there was no bruising or tenderness. This settled spontaneously. At the case conference we decided that non-accidental injury was a possibility and follow-up by a social worker was arranged. Before he was discharged a repeat bleeding time was two minutes; further clotting studies were requested, but the specimen clotted and a second specimen was not sent. After he was discharged the mother complained that the child had a nosebleed and also bled from the tongue, and finally a further large haematoma appeared on the anterior chest wall. He was readmitted and investigation this time showed: haemoglobin concentration $7.9 \mathrm{~g} / \mathrm{dl}$; prothrombin time $13 \mathrm{~s}(12 \mathrm{~s})$; partial thromboplastin time $80 \mathrm{~s}$ (48 s); platelet concentration $275 \times 10^{9} / 1 \quad\left(275000 / \mathrm{mm}^{3}\right)$; bleeding time $6 \mathrm{~min}$ (but oozed later); factor VIII 1\%. A boy was born to the mother, and he also had severe haemophilia.

\section{Case 2}

A girl was first admitted at age 9 months because of a possible head injury, after having apparently fallen from a bed. She was the only child of a young unmarried mother. Examination was unremarkable, and there was no relevant family history. Routine investigation at that time showed a haemoglobin concentration of $10.2 \mathrm{~g} / \mathrm{dl}$, with iron-deficient film and "sufficient" platelets. Epistaxes were suggested as a possible 